\title{
Implications of mitochondrial DNA mutations and mito- chondrial dysfunction in tumorigenesis
}

\author{
Jianxin $\mathrm{Lu}^{1}$, Lokendra Kumar Sharma ${ }^{2}$, Yidong Bai ${ }^{1,2}$ \\ ${ }^{I}$ Zhejiang Provincial Key Laboratory of Medical Genetics, School of Laboratory Medicine and Life Science, Wenzhou Medical \\ College, Wenzhou 325035, China; ${ }^{2}$ Department of Cellular and Structural Biology, University of Texas Health Science Center at \\ San Antonio, San Antonio, Texas 78229, USA
}

\begin{abstract}
Alterations in oxidative phosphorylation resulting from mitochondrial dysfunction have long been hypothesized to be involved in tumorigenesis. Mitochondria have recently been shown to play an important role in regulating both programmed cell death and cell proliferation. Furthermore, mitochondrial DNA (mtDNA) mutations have been found in various cancer cells. However, the role of these mtDNA mutations in tumorigenesis remains largely unknown. This review focuses on basic mitochondrial genetics, mtDNA mutations and consequential mitochondrial dysfunction associated with cancer. The potential molecular mechanisms, mediating the pathogenesis from mtDNA mutations and mitochondrial dysfunction to tumorigenesis are also discussed.
\end{abstract}

Keywords: mitochondrial DNA mutation, cancer, ROS, apoptosis

Cell Research (2009) 19:802-815. doi:10.1038/cr.2009.69; published online 16 June 2009

\section{Introduction}

Mitochondria are ubiquitous organelles in eukaryotic cells whose primary role is to generate energy supplies in the form of ATP through oxidative phosphorylation [1]. The oxidative phosphorylation chain is composed of five protein complexes: NADH-ubiquinone oxidoreductase as complex I, succinate-ubiquinone oxidoreductase as complex II, ubiquinone-cytochrome $c$ oxidoreductase as complex III, cytochrome $c$ oxidase as complex IV and ATP synthase as complex V. Oxidative phosphorylation, defined as the oxidation of electron-carriers by oxygen and concomitant ATP production, provides $90 \%$ of the cellular chemical energy required in various biological functions. Recent studies have also shown that mitochondria play a central role in apoptosis $[2,3]$ and cell proliferation [4]. Mitochondria are also major factors in modulating calcium signaling $[5,6]$, which is a universal second messenger.

Over the last 20 years, mitochondrial dysfunction, including that associated with mtDNA mutations, has been

Correspondence: Yidong Bai

Tel: +1-210-567-0561; Fax: +1-210-567-3803

E-mail: baiy@uthscsa.edu identified in human diseases, including seizure, ataxia, cortical blandness, dystonia, exercise intolerance, ophthalmoplegia, optic atrophy, cataracts, diabetes mellitus, short stature, cardiomyopathy, sensorineural hearing loss and kidney failure $[7,8]$. Large rearrangements or deletions of the mitochondrial genome and about 200 point mutations, including those in genes encoding proteins for subunits of complex I, III, IV and V, rRNAs and tRNAs, have been linked to a variety of clinical disorders [9, 10]. Accumulation of mtDNA mutations has also been suggested to play a major role in aging and the development of various age-related degenerative diseases [11]. Interestingly, high levels of mtDNA mutations have been found in many tumors and cancer cells [12-14].

\section{Mitochondrial genome and mitochondrial genetics}

The mammalian mitochondrial genome is a doublestranded circular DNA of $\sim 16500$ nucleotides $[15,16]$. It contains 37 genes encoding 13 peptides for the oxidative phosphorylation apparatus, as well as 22 tRNAs and 2 rRNAs essential for protein synthesis within mitochondria. Besides these coding regions, a displacement loop (D-loop) is also present which contains elements regulating mtDNA replication and transcription.

Most mammalian cells contain hundreds or thousands 
of copies of mitochondrial genomes [1]. Since mtDNA is in the proximity of reactive oxygen species (ROS) generation sites (the byproduct of oxidative phosphorylation) and mitochondria have relatively less sophisticated DNA protection or repair systems, mtDNA is therefore vulnerable to high mutation rates [8]. As a result, the mtDNA within a cell could be a blend of both wild type and mutant species, a condition called 'heteroplasmy'. The normal situation, in which all mtDNAs are identical, is referred to as 'homoplasmy'. The neutral polymorphisms are most likely homoplasmic, whereas the pathogenic mutations are usually heteroplasmic in nature. It is expected that, due to the multiplicity of mitochondrial genomes in each cell, a threshold of mutant mtDNA must be reached before cellular dysfunction caused by defective mitochondria becomes apparent.

Because mtDNA replication and segregation are not synchronized with nuclear DNA, daughter cells from the same progenitor could have different mtDNA genotypes [8]. When the pathogenic threshold is surpassed in certain cells, the phenotype would change. This explains the time-related and tissue-specific variability of clinical features displayed in mtDNA-related disorders.

\section{Warburg hypothesis and abnormal mitochondria in cancer cells}

Cancer cells constitutively upregulate glucose metabolism, even in the presence of abundant oxygen, and synthesize ATP mainly through 'aerobic glycolysis', a metabolic state that is linked to high glucose uptake and lactate production. To explain the fact that cancer cells were high in fermentation and low in respiration, Warburg [17] proposed that cancer originated from a nonneoplastic cell that adopted anaerobic metabolism as a means of survival after injury to its respiratory system, which led to the notion that tumors were initiated by persistent damage to the mitochondria. Since then, changes in the number, shape and function of mitochondria have been reported in various cancers [18]. The bioenergetic switch from mitochondrial oxidative phosphorylation to glycolysis has been suggested to be a marker of tumor development or the bioenergetic signature of cancer [1921]. Furthermore, mitochondrial dysfunction has been shown to initiate critical signaling pathways that regulate cell growth $[4,22]$. Recent studies suggested that defects in mitochondrial respiration led to elevated levels of NADH, which could subsequently inactivate PTEN through a redox modification mechanism [23]. Inhibition of PTEN could activate protein kinase B (Akt) [23], and Akt was shown to enhance glycolysis, possibly through the effects on its key rate-limiting step, phosphoryla- tion of newly acquired glucose by hexokinases [24]. Akt also triggers an increase in cell survival [25], which is commonly observed in cancer cells [26]. Furthermore, inhibition of oxidative phosphorylation by oligomycin in lung carcinoma was shown to trigger a rapid increase in aerobic glycolysis demonstrating that tumor cells can become glycolytic as a result of suppression of mitochondrial energy production [27]. However, when glycolysis was suppressed, tumor cells were unable to sufficiently upregulate mitochondrial oxidative phosphorylation, indicating partial mitochondrial impairment [28]. Rapidly growing tumors easily become hypoxic owing to the inability of the local vasculature to supply an adequate amount of oxygen. As a result, tumor cells upregulate the glycolytic pathway by inducing hypoxia-inducible factor 1 (HIF-1) [29]. HIF-1 plays an important role in tumorigenesis and will be described in detail in a later section.

\section{mtDNA mutations in cancers}

It is interesting to note that, even before DNA sequencing technology was available, abnormal mtDNA was observed in leukemic myeloid cells using electron microscopy $[30,31]$. Subsequently, mutations in both the non-coding and coding regions of the mtDNA have been identified in various types of human cancers, and the majority of the mutations appeared to be homoplasmic in nature $[32,33]$. One of the first comprehensive studies of mtDNA in cancer cells demonstrated that among 10 colorectal cancer lines, seven of them exhibited mutations in their mtDNA content [12]. The mtDNA mutations were found in rRNA (12S and 16S) genes, subunits of complex I (ND1, ND4L and ND5), complex III (cytochrome $b$ ) and complex IV (COXI, COXII and COXIII). A total of 11 out of 12 mutations were nucleotide substitutions, while the remaining mutation was a single base pair insertion. Moreover, all of these mutations were true somatic mutations and did not exist in constitutional mtDNA from the same patient. Similarly, mtDNA mutations within the D-loop control region have been reported as a frequent event in ovarian, gastric and hepatocellular carcinomas [34-36]. Specifically, it was suggested that in the D-loop region, a poly-C stretch (C-tract), termed the D310 region, is more susceptible to oxidative damage and electrophilic attack compared with other regions of mtDNA [37]. In another study, it was found that in renal carcinoma, mtDNA harbored disruptive point mutations in eight of nine tumors, seven tumors with complex I genes mutations [38], and one with mutation in a complex III gene.

Increasingly systematic analyses of mtDNA have been performed in various cancers, and in this review, we sur- 
veyed 101 papers published between 1998 and 2008, using Medline searches with "mtDNA mutation cancer/tumor' as keywords. The results of these analyses are summarized in Tables 1-4. From these reports, we found that the majority of identified mutations (635) were located in the D-loop region (Table 3), as this region can accumulate variances quite easily. In addition, some authors focused solely on the D-loop region when attempting to detect mtDNA mutations. Interestingly, more mutations have been found in genes encoding complex I subunits (Table 1), with 593 mutations reported at the occurrence of $9.3 \%$, compared with genes for other respiratory complexes (Table 2). Similar levels of mutations have been reported in tRNA and rRNA genes, with frequencies of

Table 1 Complex I mutations

\begin{tabular}{lll}
\hline Region & Cancer types & Description \\
\hline ND1 & Leukemia [112-114], colorectal cancer [12,115, 116], cervical tumor & A total of 116 mutations were reported, in- \\
& [117], lung cancer [118], skin cancer [119, 120], ovarian cancer [34], & cluding 63 missense mutations, 42 silent \\
& parathyroid gland tumor [121], renal cancer [38], thyroid tumor [122- & mutations, 4 nonsense mutations, 3 insertions \\
& 127], renal oncocytoma [38, 128], head and neck cancer [79, 129], gas- & and 4 deletions.
\end{tabular}
trointestinal tract tumor [130,133], prostate cancer [131], breast cancer [132].

ND2 Breast cancer [134, 135], cervical tumor [117], lung cancer [118], brain tumor [136], skin cancer [119, 120], oral cancer [137-139], parathyroid gland tumor [121], pancreatic cancer [134], prostate cancer [134], renal tumor [140], thyroid tumor [32, 122-126, 141], head and neck cancer [79, 129], gastrointestinal tract tumor [130], glioma [142].

ND3 Bladder cancer [143], cervical tumor [117], colorectal cancer [116], lung cancer [118], thyroid tumor [122, 123, 125, 126], parathyroid gland tumor [121], head and neck cancer [79, 129], gastrointestinal tract tumor [130], renal cancer [144], oral cancer [138, 139].

ND4 Leukemia [112, 113], bladder cancer [143, 145], brain tumor [146], cervical tumor [117], parathyroid gland tumor [121], colorectal cancer [116], head and neck cancer [79, 143], lung cancer [118], ovarian cancer [34], renal tumor [38, 128, 140], thyroid tumor [122-126, 141], gastrointestinal tract tumor [130], prostate cancer [131], oral cancer [139], breast cancer [132].

ND4L Cervical tumor [117], colorectal cancer [12, 116], head and neck cancer [79], thyroid tumor [123, 125, 126], lung cancer [118], brain tumor [136], skin cancer [120], ovarian cancer [34], parathyroid gland tumor [121], prostate cancer [147], gastrointestinal tract tumor [130].

ND5 Leukemia [112, 114], bladder cancer [143], breast cancer [132, 134], cervical tumor [117], parathyroid gland tumor [121], colorectal cancer [115, 134, 148], lung cancer [118], skin cancer [119, 120], pancreatic cancer [134], prostate cancer [131, 134], renal tumor [128, 140, 144, 149], thyroid tumor [123-125, 141, 150], esophageal cancer [151], head and neck cancer [79], gastrointestinal tract tumor [130, 152], glioma [142].

ND6 Leukemia [112], breast cancer [134], cervical tumor [117], parathyroid gland tumor [121], colorectal cancer [134], lung cancer [118], ovarian cancer [34], pancreatic cancer [134], prostate cancer [134], thyroid tumor [122, 124-126, 141], renal cancer [38], head and neck cancer [79], gastrointestinal tract tumor [130, 152], glioma [142].

A total of 92 mutations were reported, including 41 missense mutations, 48 silent mutations, 2 nonsense mutations and 1 deletion. The $\mathrm{A} 4769 \mathrm{G}$ and $\mathrm{A} 4917 \mathrm{G}$ mutations were found in 4 different tumors.

A total of 26 mutations were reported, including 12 missense mutations, 13 silent mutations and 1 deletion.

A total of 152 mutations were reported, including 52 missense mutations, 91 silent mutations, 2 nonsense mutations, 2 insertions and 5 deletions.

A total of 18 mutations were reported, including 8 missense mutations and 10 silent mutations.

A total of 156 mutations were reported, including 63 missense mutations, 86 silent mutations, 3 nonsense mutations, 2 insertions and 2 deletions.

A total of 33 mutations were reported, including 11 missense mutations, 20 silent mutations and 2 deletions. 
Table 2 Complex III, IV and V mutations

\begin{tabular}{ll}
\hline Region & Cancer types \\
\hline Cyt $b$ & Leukemia $[112,113]$, bladder cancer [143], brain tumor [146], \\
& breast cancer [132, 134], colorectal cancer [12], lung cancer [118], \\
& ovarian cancer [34], pancreatic cancer [134], parathyroid gland \\
& tumor [121], prostate tumor [134, 147, 153], skin cancer [120], thy- \\
& roid tumor [122-126], head and neck cancer [79], gastrointestinal \\
& tract tumor [130], nasopharyngeal carcinoma [154], glioma [155]. \\
& Breast cancer [134], colorectal cancer [116, 156], lung cancer [118], \\
& brain tumor [136], skin cancer [120], parathyroid gland tumor [121], \\
& pancreatic cancer [134], prostate cancer [44, 134], thyroid tumor \\
& {$[122,124-126]$, ovarian cancer [34], head and neck cancer [79], } \\
& gastrointestinal tract tumor [130, 133], glioma [155], hepatocellular \\
& cancer [157].
\end{tabular}

COII Colorectal cancer [12], breast cancer [134], head and neck cancer [79, 151], lung cancer [118], skin cancer [120], ovarian cancer [34], parathyroid gland tumor [121], thyroid tumor [122, 124-126], gastrointestinal tract tumor [130], leukemia [113].

COIII Brain tumor [146], breast cancer [134], colorectal cancer [12, 156, 158], head and neck cancer [79, 129, 151], lung cancer [118], skin cancer [120], ovarian cancer [34], parathyroid gland tumor [121], thyroid tumor [123-126, 141, 150], gastrointestinal tract tumor [130], oral cancer $[138,139]$.

ATPase6 Breast cancer [135, 159], colorectal cancer [146], head and neck cancer [79, 129, 151], lung cancer [118], skin cancer [120], parathyroid gland tumor [121], thyroid tumor [123-126], gastric tumor [152], leukemia [113].

ATPase8 Breast cancer [134], colon cancer [134], liver cancer [41], ovarian cancer [34], pancreatic cancer [134], parathyroid gland tumor [121], prostate cancer [134], thyroid tumor [124, 125], gastrointestinal tract tumor [130], head and neck cancer [79, 129, 151].
Description

A total of 93 mutations were reported, including 50 missense mutations, 38 silent mutations, 2 nonsense mutations and 3 deletions.

A total of 86 mutations were reported, including 22 missense mutations, 62 silent mutations and 2 insertions.

A total of 46 mutations were reported, including 12 missense mutations, 33 silent mutations and 1 deletion.

A total of 54 mutations were reported, including 24 missense mutations, 25 silent mutations, 1 nonsense mutation, 1 insertion and 3 deletions.

A total of 55 mutations were reported, including 34 missense mutations, 20 silent mutations and 1 nonsense mutation.

A total of 9 mutations were reported, including 2 missense mutations and 7 silent mutations.

Table 3 D-loop mutations

\begin{tabular}{lll}
\hline Region & Cancer types & Description \\
\hline D-loop & Leukemia [112, 113], bladder cancer [143, 160], breast cancer [132, 161- & A total of 635 mutations were reported, in- \\
& 165], cervical tumor [160, 166, 167], colorectal cancer [12, 116, 148, 158, & cluding 510 point mutations, 56 deletions \\
& 168-170], endometrial tumor [160, 171-173], head and neck cancer [79, & (among them 2 were 50 bp deletions) and 69 \\
& $129,143,151,174-176]$, liver cancer [180, 181], lung cancer [143, 177, & insertions. Mutations at position 310 were \\
& $182,183]$, brain tumor [136], skin cancer [119, 120], oral cancer [137, & detected in several types of cancers. A263G, \\
& 138, 160, 184], parathyroid gland tumor [121], prostate cancer [131, 137, & C150T, C16223T, C16519T, G16390A, \\
& 185-187], renal tumor [137, 149], stomach cancer [137, 178, 181], thyroid & G207A, G94A, T146C, T152C, T16189C, \\
& cancer [121, 137, 188], uterine carcinoma [137], nasopharyngeal carci- & T195C, T204C, T72C were also found to as- \\
& noma [154], ovarian cancer [189], gastrointestinal tumor [130, 179, 190, & sociate with cancers by different groups.
\end{tabular}
193], hepatocellular cancer [35, 157, 181, 191, 192], glioma [155, 194], astrocytoma [195], Barrett's cancer [196], osteosarcoma [197], Ewing's sarcoma[198], gallbladder carcinoma [199]. 
$3.7 \%$ and $4.3 \%$, respectively (Table 4 ), although mutations in tRNA genes are much more prevalent in patients with other mitochondrial diseases. The relatively common 4977 bp deletion mutation was detected in gastric cancer [39], lung cancer [40] and liver cancer cells [41].

The direct impact of several mtDNA mutations on tumorigenesis has been tested with the cybrid (cytoplasmic hybrid) system, where mtDNA is singled out for analysis [42]. Cybrids carrying a pathogenic mutation at position 8993 or 9176 in the mtDNA ATP synthase subunit 6 gene (ATP6) derived from patients with mitochondrial encephalomyopathy were investigated for tumorigenesis in a nude mouse assay. It was found that the ATP6 mutations conferred an advantage in the early stage of tumor growth [43]. In a separate study, the T8993G mutation was introduced into the $\mathrm{PC} 3$ prostate cancer cell line, and the resulting mutant cybrids were reported to generate tumors that were seven times larger than the wild-type cybrids [44]. Further, as prostate cancer often metastasizes to bone, the above cybrids were co-inoculated in a nude mouse system with bone stromal cells [45]. Growth acceleration in cybrids with mtDNA mutation was demonstrated in the bone microenvironment, and this effect was further shown to be likely mediated by upregulation of fibroblast growth factor 1 (FGF-1) and focal adhesion kinase (FAK) [45].

In another investigation, the contribution of mtDNA mutations to tumor cell metastasis was also analyzed [46].
It was found that the mtDNA variant, which delivered the highest metastatic potential, contained G13997A and 13885 insC mutations in the ND6 gene.

We recently examined the contribution of mtDNA mutations and mitochondrial dysfunction in tumorigenesis using human cell lines carrying a frame-shift mutation in the complex I subunit 5 gene (ND5); the same homoplasmic mutation was also previously identified in a human colorectal cancer cell line [12]. With increasing mutant ND5 mtDNA content, respiratory function, including oxygen consumption and ATP generation through oxidative phosphorylation, declined progressively, whereas lactate production and dependence on glucose increased. Both heteroplasmic and homoplasmic mtDNA mutation caused an increased production of mitochondrial ROS. However in cells with heteroplasmic ND5 mutation, the cytosolic ROS level was somewhat reduced, probably due to the upregulation of antioxidant enzymes. As a result, only cells with homoplasmic ND5 mutation exhibited enhanced apoptotic potency. Furthermore, anchoragedependence and tumor-forming capacity of cells carrying wild type and mutant mtDNA were tested by a growth assay in soft agar and subcutaneous implantation of the cells in nude mice. Surprisingly, the cell line carrying the heteroplasmic ND5 mtDNA mutation showed significantly enhanced tumor growth, whereas tumor formation was inhibited for cells with the homoplasmic form of the same mutation [47].

Table 4 tRNA and rRNA mutations

\begin{tabular}{|c|c|c|}
\hline Region & Cancer types & Description \\
\hline tRNA & $\begin{array}{l}\text { Breast cancer [134], colon cancer [134], liver cancer [180], lung cancer } \\
{[143,200] \text {, brain tumor [136], skin cancer [120], ovarian cancer [34], }} \\
\text { parathyroid gland tumor [121], pancreatic cancer [134], prostate cancer } \\
{[131,134,147] \text {, renal tumor }[128,140,201] \text {, thyroid tumor }[122,124 \text {, }} \\
125,127] \text {, head and neck cancer [79], gastrointestinal tract tumor [130], } \\
\text { nasopharyngeal carcinoma [154], splenic lymphoma [202], leukemia } \\
{[114] \text {. }}\end{array}$ & $\begin{array}{l}\text { A total of } 56 \text { mutations were reported, in- } \\
\text { cluding } 54 \text { point mutations and } 2 \text { deletions. } \\
\text { A } 3234 \mathrm{G} \text { of tRNA }{ }^{\text {leu }} \text { has been reported in } \\
\text { lung, colon and renal cancers. Additional } \\
\text { mutations have been found in tRNA }^{\text {asp }} \text {, } \\
\text { tRNA }^{\text {thr }} \text { and tRNA }{ }^{\text {phe }} \text { genes. }\end{array}$ \\
\hline 12S rRNA & $\begin{array}{l}\text { Leukemia [112], colorectal cancer }[12,116] \text {, endometrial cancer [172], } \\
\text { ovarian carcinoma [34], parathyroid gland tumor [121], prostate can- } \\
\text { cer [147], thyroid cancer }[124,125] \text {, gastrointestinal tract tumor [130, } \\
203] \text {, head and neck cancer [79], nasopharyngeal carcinoma [154], re- } \\
\text { nal cancer [144]. }\end{array}$ & $\begin{array}{l}\text { A total of } 53 \text { mutations were reported, in- } \\
\text { cluding } 47 \text { point mutations, } 5 \text { insertions and } \\
1 \text { deletion. The T710C mutation has been } \\
\text { reported in both colorectal and thyroid can- } \\
\text { cers. }\end{array}$ \\
\hline
\end{tabular}




\section{ROS generation and its role in tumorigenesis}

ROS are a collective term, which includes superoxide, hydrogen peroxide and the hydroxyl free radical [48]. The mitochondrial electron transport chain is a major source of ROS, as some of the electrons passing to molecular oxygen are instead leaked out of the chain. It has been estimated that generation of these partially reduced oxygen molecules comprises about $2-4 \%$ of the oxygen consumed [48]. ROS are highly active and can cause damage to different cellular components including mtDNA $[49,50]$. The damaged mtDNA, if not repaired properly, produces mtDNA mutations, which, in turn, could initiate tumorigenesis and sustain cancer development.

In addition to their cytotoxic effects, low levels of ROS participate in the regulation of many cellular pathways [51, 52]. The interaction of ROS with lipid species and thiol-containing proteins is important in cell growth and differentiation [53, 54]. It was suggested that a threshold level of ROS (ROS window) is required for normal/cancer cell functions; above this level, cell death is activated and below it, proliferation is blocked [55-57]. ROS have been shown to be involved in the transmission of survival and proliferation signals associated with tumor promotion and maintenance. For example, $\mathrm{H}_{2} \mathrm{O}_{2}$ has been demonstrated to activate the receptor tyrosine kinase [58, 59], Ras-mitogen-activated protein kinase (Ras-MAPK) [60, 61] and phosphatidylinositol 3' -kinase (PI3K) pathways [58]. ROS also mediate the stress signaling pathways involving nuclear factor-kappa B (NF-kB) [62] and the c-Jun $\mathrm{NH}_{2}$-terminal kinase (JNK) [63]. The window hypothesis has also been supported by the observation that removal of $\mathrm{H}_{2} \mathrm{O}_{2}$ from the cellular environment by catalase blocks cell proliferation via down-regulation of MAPK activity [64]. Similarly, ROS are also capable of preventing caspase activation, as in the case of protection of stimulated neutrophils from the toxic effects of oxidative stress [65].

The association of oxidative stress with tumorigenesis has been implicated in the induction of skin cancer by ultraviolet radiation, leukemia by $\gamma$-radiation and others, including lung cancer, by smoking. The role of ROS in tumor development has been supported by the demonstration that normal cells exposed to ROS show increased proliferation [54] and expression of growth-related genes [66-68]. Furthermore, a large number of cancer cells are known to produce more ROS than non-cancer cells [69, 70]. These observations suggest that ROS stimuli may contribute to cancer initiation, maintenance and development in vivo.

Rapid cell proliferation in cancer results in a surge of oxygen consumption and thus, tumor tissues suffer from hypoxia. The transcription factor, HIF-1 (Hypoxia inducible factor-1), is the key mediator of the hypoxia response through regulating genes involved in metabolism, angiogenesis, cell cycle and apoptosis [71]. Transcriptional activation of genes, such as vascular endothelial growth factor and glucose transporter, by HIF1 is among the best-understood examples of regulation of angiogenesis and metabolism during the adaptation to hypoxic conditions [72].

In addition to upregulating the glycolytic pathway, HIF-1 was also shown to inhibit mitochondrial biogenesis and respiration in a renal cell carcinoma model by repression of C-MYC activity [73]. Importantly, C-MYC was required for the expression of coactivator, PGC-1 $\beta$, which is a key regulator of mitochondrial biogenesis [74]. Alternatively, HIF-1 downregulates oxidative phosphorylation through activation of pyruvate dehydrogenase kinase 1 (PDK1) [75, 76]. PDK1 inactivates the TCA cycle enzyme, pyruvate dehydrogenase, which converts pyruvate to acetyl-CoA. Interestingly, it was also demonstrated that HIF-1 could modulate respiration efficiency in hypoxic cells by regulating complex IV subunit 4 isoforms. Such regulation has important implications in ATP production, oxygen consumption and ROS generation [77].

Emerging evidence has indicated the important role of mitochondrial ROS generation during hypoxic activation of HIF [78]. Further, expression of the nuclear-transcribed, mitochondrial-targeted ND2 mutants resulted in enhanced tumor growth, which was accompanied by increased ROS production and HIF-1 $\alpha$ induction. These phenotypes were reversible by a complex III inhibitor, ascorbate [79].

\section{Apoptosis, another link between mitochondrial dysfunction and tumorigenesis}

Apoptosis is a process whereby a series of proteases, called caspases, are activated through a complex signaling cascade leading to energy-dependent cell death [80]. Defects in apoptosis are among the major causes of tumorigenesis [81]. Mitochondria play an important role in regulating apoptosis [82]. A recent study investigated the effects of mitochondrial respiratory chain modulation on apoptosis [83]. It was reported that defects in the respiratory chain could either promote or inhibit cell death, depending on the specific alteration in electron flow [83]. The initiation of apoptosis can also occur in the mitochondria through stimulated ROS production. Low levels of ATP and high levels of cytosolic calcium, are usually associated with mitochondrial defects and reported as signals to induce apoptosis [84]. Interestingly, in some 
cases, ROS mediate both pro- and anti-apoptotic effects, depending on their concentrations [85].

Among studies of cell death resistance due to mitochondrial dysfunction in cancer cells, it was reported that mitochondrial respiration defects led to activation of the Akt survival pathway. As mentioned earlier, this up-regulation of Akt was suggested to result from an increase in $\mathrm{NADH}$, the substrate of respiratory complex I, which then inactivates PTEN through a redox modification mechanism [23]. In another study, modulation of mitochondrial function by up-regulation of mitochondrial chaperones has been implicated in the survival of cancer cells [86, 87]. Heat shock protein 90 and its mitochondrial-related molecule, TRAP-1, were suggested to interact with cyclophilin D to inhibit cell death [87], whereas Hsp60 was shown to orchestrate a broad cell survival program centered on stabilization of mitochondria to restrain p53 function [86].

Interestingly, it was also reported that the molecular mechanism through which ATP6 mutations at positions 8993 and 9176 promote tumorigenesis is by preventing apoptosis [43], although the details of such a signaling pathway remain unclear.

\section{Retrograde regulation and other mitochondrial sig- naling mechanisms in cancer cells}

Retrograde regulation is a communication pathway from the mitochondria to the nucleus that is used to describe the cellular response to the changes in the functional state of mitochondria [88]. The first evidence of altered nuclear gene expression in response to mitochondrial dysfunction in mammalian cells came from studies showing increased mRNA levels coding for various mitochondrial proteins in several types of mtDNA-less $\left(\rho^{0}\right)$ cells $[89,90]$. One of the mechanisms suggested to play a role in the retrograde response was mitochondrial stress, which is supported by changes in mitochondrial membrane potential and elevation of calcium levels [88]. Using $\rho^{0}$ human osteosarcoma $143 \mathrm{~B}$ cells and cybrid cell lines carrying mutated mitochondrial tRNAs, it was shown that respiratory deficiency and the associated calcium increase induced the activation of CaMKIV (calcium/calmodulin kinase IV). The activation of CaMKIV in turn activated CREB (cAMP-responsive element-binding protein) and Egr1 (early growth response gene-1) through PKC-mediated phosphorylation $[22,91]$. In a recent report, such mitochondrial-nuclear communication was further divided into two different pathways: one caused by a reduction in respiration and another, named intergenomic signaling, which requires mtDNA [92]. Using DNA microarrays in the budding yeast Saccharomy- ces cerevisiae, it was shown that intergenomic signaling functions in coordinating mitochondrial and nuclear gene expression.

In a Drosophila system, it was shown that mitochondrial dysfunction activated the production of both AMP and ROS, the former stimulating AMPK and p53, and causing the loss of cyclin $\mathrm{E}$, and the latter turning on JNK, FOXO and other G1-S cell cycle checkpoint molecules. These findings demonstrate mitochondrial retrograde regulation of cell cycle progression via AMP and ROS at sublethal concentrations through independent signaling molecules [93].

In tumor cells, retrograde signaling has also been demonstrated as a pathway that links mitochondrial dysfunction to oncogenic events. In paraganglioma, mutations in the mitochondrial tumor suppressor, succinate dehydrogenase $(\mathrm{SDH})$ result in the accumulation of succinate, which was shown to inhibit HIF- $\alpha$ prolyl hydroxylases, leading to the stabilization and activation of HIF$1 \alpha$ [94]. Thus, succinate was suggested as a retrograde linkage between abnormal mitochondrial metabolism and oncogenesis. In an early study, cytoplasts (cells depleted of nuclei) from tumor cells were shown to transfer tumorigenic properties when fused with nuclei from normal cells, indicating that cytoplasmic factors can induce malignant phenotypes [95]. Depletion and partial depletion of mtDNA by a mitochondrial-specific ionophore, carbonyl cyanide m-chlorophenyl hydrazone, induced increasingly invasive behavior in $\mathrm{C} 2 \mathrm{C} 12$ rhabdomyoblasts and A549 human lung carcinoma cells [96-98]. In such cases, a number of genes involved in $\mathrm{Ca}^{2+}$ response, glucose metabolism, oncogenesis and apoptosis were upregulated [99]. Further, in such systems, it was shown that calcineurin-mediated activation of the insulin-like growth facor-1 (IGF-1) receptor pathway and metabolic shift to the glycolytic pathway, provided a survival advantage to cells under mitochondrial stress caused by mtDNA depletion [100]. Recently, it has been shown that cells treated with a human carcinogen, dioxin, displayed resistance to apoptosis, increased expression of the tumor marker, cathepsin L, and a high degree of invasiveness, which are linked to the triggering of a signaling pathway that promotes tumor progression in vivo through directly targeting mitochondrial transcription and induction of mitochondrial stress signaling [101].

Retrograde signaling induces the expression of a number of tumor-specific marker genes, such as extracellular matrix protease, TGF- $\beta$ and epiregulin, as well as other genes that control cell growth and proliferation, such as PKC, JNK/MAPK, CREB and NF- $\mathrm{KB}$ [88]. A proteomics approach was also used to gain insight into the nuclear gene targets of mitochondrial stress signaling $[102,103]$. 
In one study, the potential role for one of the identified retrograde response proteins, UQCRC1 (encoding complex III subunit core protein 1), was analyzed, and it was found to be highly expressed in breast and ovarian tumors [102].

\section{Mitochondrial defects and genome instability}

Since mitochondria are the major source of cellular ATP production, it is likely that mitochondrial dysfunction leads to a reduction in ATP levels that may affect the ATP-dependent pathways involved in transcription, DNA replication, DNA repair and DNA recombination. Mitochondria are also involved in the biosynthesis of deoxyribose nucleoside triphosphates (dNTP) [104, 105]. Taken together, it is conceivable that mitochondrial deficiency could lead to mutagenesis in the nuclear genome. In yeast, it was reported that mitochondrial dysfunction caused by respiration inhibition, mtDNA depletion or mtDNA deletion resulted in a twofold to threefold increase in the nuclear DNA mutation frequency [106]. In human cell lines depleted of mtDNA, it was reported that dNTP pools were affected, and in particular, a threefold reduction in dTTP pools was detected [107]. Since imbalanced dNTP pools had been shown to be mutagenic [108], a molecular mechanism linking mitochondrial dysfunction to nuclear genome instability was proposed [107]. Interestingly, disruption of mitochondrial function in mouse zygotes led to telomere attrition, telomere loss, and chromosome fusion and breakage, mediated by alterations in ROS production [109].

\section{Significance of investigation of mtDNA mutations in cancer}

Despite tremendous progress in identifying and characterizing nuclear oncogenes, tumor suppressor genes and their roles in cancer development, there are still many aspects of tumorigenesis that cannot be explained. The role of mitochondria, specifically mtDNA mutations, remains largely unclear. Although evidence suggests that some mtDNA mutations do play a role in certain stages of cancer development, there are still multiple potential pitfalls in such investigations [110]. Special caution and general guidelines should be followed in this very important yet complicated line of research [111].

Based on our recent results [47] and studies from other labs, we propose that mtDNA mutations could function in cancer development as follows: in the initial stage, cancer cells are very mutagenic either because of a carcinogenic insult or due to the compromised repair mechanism, and mtDNA is more likely to be mutated at this stage. Because of the replicative advantage of mutant mtDNA molecules, such as that previously described for mtDNA carrying the mutation associated with the mitochondrial encephalomyopathy, mtDNA mutations are enriched to a certain level of heteroplasmy which would enhance tumor progression due to either the elevated ROS generation, which in turn activates the oncogenic pathways, or the increase in genome instability, or both. However, after transformation, it may become more important to have a functional respiratory chain than an inhibited one to sustain rapid cell proliferation. In some cases, the mutant mtDNAs causing severe mitochondrial defects are selected against and diluted out; in other cases, residual mutant mtDNA might escape the selection. In late stages of cancer, the cells are progressively adapted to a glycolytic metabolism because of the hypoxic environment. This may lead to the selection of cells in which the mutations make them mitochondrial function-independent and, therefore, cells with homoplasmic mtDNA mutations may become predominant in such tumors. If this hypothesis is correct, the involvement of mtDNA mutations may, in fact, be much more prevalent in early stage cancers than originally thought.

\section{Acknowledgments}

The work carried out in the authors' laboratories was supported by the NIA/NIH (R01 AG025223 to YB) and Wendy Will Case Cancer Fund (to YB). We thank Hezhi Fang, Lijun Shen, Jia Wei, Zhinan Ding, Jing He and Tao Chen of Wenzhou Medical College for help in preparation of the tables.

\section{References}

1 Attardi G, Schatz G. Biogenesis of mitochondria. Annu Rev Cell Biol 1988; 4:289-333.

2 Wang $X$. The expanding role of mitochondria in apoptosis. Genes Dev 2001; 15:2922-2933.

3 Kroemer G, Reed JC. Mitochondrial control of cell death. Nat Med 2000; 6:513-519.

4 Rustin P. Mitochondria, from cell death to proliferation. Nat Genet 2002; 30:352-353.

5 Rizzuto R, Bernardi P, Pozzan T. Mitochondria as all-round players of the calcium game. J Physiol 2000; 529 Pt 1:37-47.

6 Babcock DF, Hille B. Mitochondrial oversight of cellular $\mathrm{Ca}^{2+}$ signaling. Curr Opin Neurobiol 1998; 8:398-404.

7 Wallace DC. Mitochondrial DNA in aging and disease. Sci Am 1997; 277:40-47.

8 DiMauro S, Schon EA. Mitochondrial DNA mutations in human disease. Am J Med Genet 2001; 106:18-26.

9 DiMauro S. Mitochondrial DNA medicine. Biosci Rep 2007; 27:5-9.

10 Reeve AK, Krishnan KJ, Turnbull D. Mitochondrial DNA mutations in disease, aging, and neurodegeneration. Ann $N Y$ Acad Sci 2008; 1147:21-29. 
11 Wallace DC. A mitochondrial paradigm for degenerative diseases and ageing. Novartis Found Symp 2001; 235:247-263; discussion 263-246.

12 Polyak K, Li Y, Zhu H, et al. Somatic mutations of the mitochondrial genome in human colorectal tumours. Nat Genet 1998; 20:291-293.

13 Penta JS, Johnson FM, Wachsman JT, Copeland WC. Mitochondrial DNA in human malignancy. Mutat Res 2001; 488:119-133.

14 Hochhauser D. Relevance of mitochondrial DNA in cancer. Lancet 2000; 356:181-182.

15 Anderson S, Bankier AT, Barrell BG, et al. Sequence and organization of the human mitochondrial genome. Nature 1981; 290:457-465.

16 Attardi G. Animal mitochondrial DNA: an extreme example of genetic economy. Int Rev Cytol 1985; 93:93-145.

17 Warburg O. On the origin of cancer cell. Science 1956; 123:309-314.

18 Pedersen PL. Tumor mitochondria and the bioenergetics of cancer cells. Prog Exp Tumor Res 1978; 22:190-274.

19 Bando H, Atsumi T, Nishio T, et al. Phosphorylation of the 6-phosphofructo-2-kinase/fructose 2,6-bisphosphatase/ PFKFB3 family of glycolytic regulators in human cancer. Clin Cancer Res 2005; 11:5784-5792.

20 Chowdhury SK, Gemin A, Singh G. High activity of mitochondrial glycerophosphate dehydrogenase and glycerophosphate-dependent ROS production in prostate cancer cell lines. Biochem Biophys Res Commun 2005; 333:1139-1145.

21 Cuezva JM, Krajewska M, de Heredia ML, et al. The bioenergetic signature of cancer: a marker of tumor progression. Cancer Res 2002; 62:6674-6681.

22 Arnould T, Vankoningsloo S, Renard P, et al. CREB activation induced by mitochondrial dysfunction is a new signaling pathway that impairs cell proliferation. EMBO J 2002; 21:5363.

23 Pelicano H, Xu RH, Du M, et al. Mitochondrial respiration defects in cancer cells cause activation of Akt survival pathway through a redox-mediated mechanism. J Cell Biol 2006; 175:913-923.

24 Gottlob K, Majewski N, Kennedy S, et al. Inhibition of early apoptotic events by Akt/PKB is dependent on the first committed step of glycolysis and mitochondrial hexokinase. Genes Dev 2001; 15:1406-1418.

25 Plas DR, Thompson CB. Akt-dependent transformation: there is more to growth than just surviving. Oncogene 2005; 24:7435-7442.

26 Elstrom RL, Bauer DE, Buzzai M, et al. Akt stimulates aerobic glycolysis in cancer cells. Cancer Res 2004; 64:38923899.

27 Lopez-Rios F, Sanchez-Arago M, Garcia-Garcia E, et al. Loss of the mitochondrial bioenergetic capacity underlies the glucose avidity of carcinomas. Cancer Res 2007; 67:9013-9017.

$28 \mathrm{Wu}$ M, Neilson A, Swift AL, et al. Multiparameter metabolic analysis reveals a close link between attenuated mitochondrial bioenergetic function and enhanced glycolysis dependency in human tumor cells. Am J Physiol Cell Physiol 2007; 292:C125-C136.

29 Wang GL, Semenza GL. General involvement of hypoxiainducible factor 1 in transcriptional response to hypoxia. Proc
Natl Acad Sci USA 1993; 90:4304-4308.

30 Clayton DA, Vinograd J. Circular dimer and catenate forms of mitochondrial DNA in human leukaemic leucocytes. J Pers 1967; 35:652-657.

31 Clayton DA, Vinograd J. Complex mitochondrial DNA in leukemic and normal human myeloid cells. Proc Natl Acad Sci USA 1969; 62:1077-1084.

32 Brandon M, Baldi P, Wallace DC. Mitochondrial mutations in cancer. Oncogene 2006; 25:4647-4662.

33 Chatterjee A, Mambo E, Sidransky D. Mitochondrial DNA mutations in human cancer. Oncogene 2006; 25:4663-4674.

34 Liu VW, Shi HH, Cheung AN, et al. High incidence of somatic mitochondrial DNA mutations in human ovarian carcinomas. Cancer Res 2001; 61:5998-6001.

35 Nomoto S, Yamashita K, Koshikawa K, Nakao A, Sidransky D. Mitochondrial D-loop mutations as clonal markers in multicentric hepatocellular carcinoma and plasma. Clin Cancer Res 2002; 8:481-487.

36 Zhao YB, Yang HY, Zhang XW, Chen GY. Mutation in Dloop region of mitochondrial DNA in gastric cancer and its significance. World J Gastroenterol 2005; 11:3304-3306.

37 Mambo E, Gao X, Cohen Y, et al. Electrophile and oxidant damage of mitochondrial DNA leading to rapid evolution of homoplasmic mutations. Proc Natl Acad Sci USA 2003; 100:1838-1843.

38 Gasparre G, Hervouet E, de Laplanche E, et al. Clonal expansion of mutated mitochondrial DNA is associated with tumor formation and complex I deficiency in the benign renal oncocytoma. Hum Mol Genet 2008; 17:986-995.

39 Kamalidehghan B, Houshmand M, Ismail P, Panahi MS, Akbari Mh. Delta mtDNA4977 is more common in non-tumoral cells from gastric cancer sample. Arch Med Res 2006; 37:730735 .

40 Dai JG, Xiao YB, Min JX, et al. Mitochondrial DNA 4977 BP deletion mutations in lung carcinoma. Indian J Cancer 2006; 43:20-25.

41 Yin PH, Lee HC, Chau GY, et al. Alteration of the copy number and deletion of mitochondrial DNA in human hepatocellular carcinoma. Br J Cancer 2004; 90:2390-2396.

42 King MP, Attardi G. Human cells lacking mtDNA: repopulation with exogenous mitochondria by complementation. Science 1989; 246:500-503.

43 Shidara Y, Yamagata K, Kanamori T, et al. Positive contribution of pathogenic mutations in the mitochondrial genome to the promotion of cancer by prevention from apoptosis. Cancer Res 2005; 65:1655-1663.

44 Petros JA, Baumann AK, Ruiz-Pesini E, et al. mtDNA mutations increase tumorigenicity in prostate cancer. Proc Natl Acad Sci USA 2005; 102:719-724.

45 Arnold RS, Sun CQ, Richards JC, et al. Mitochondrial DNA mutation stimulates prostate cancer growth in bone stromal environment. Prostate 2009; 69:1-11.

46 Ishikawa $\mathrm{K}$, Takenaga $\mathrm{K}$, Akimoto $\mathrm{M}$, et al. ROS-generating mitochondrial DNA mutations can regulate tumor cell metastasis. Science 2008; 320:661-664.

47 Park JS, Sharma LK, Li HZ, et al. A heteroplasmic, not homoplasmic, mitochondrial DNA mutation promotes tumorigenesis via alteration in reactive oxygen species generation and apoptosis. Hum Mol Genet 2009; 18:1578-1589. 
48 Chance B, Sies H, Boveris A. Hydroperoxide metabolism in mammalian organs. Physiol Rev 1979; 59:527-605.

49 Ames BN, Shigenaga MK. Oxidants are a major contributor to aging. Ann N Y Acad Sci 1992; 663:85-96.

50 Harman D. Free radicals in aging. Mol Cell Biochem 1988; 84:155-161.

51 Gamaley IA, Klyubin IV. Roles of reactive oxygen species: signaling and regulation of cellular functions. Int Rev Cytol 1999; 188:203-255.

52 Finkel T. Reactive oxygen species and signal transduction. IUBMB Life 2001; 52:3-6.

53 Lander HM. An essential role for free radicals and derived species in signal transduction. FASEB J 1997; 11:118-124.

54 Burdon RH. Superoxide and hydrogen peroxide in relation to mammalian cell proliferation. Free Radic Biol Med 1995; 18:775-794.

55 Pagano G. Redox-modulated xenobiotic action and ROS formation: a mirror or a window? Hum Exp Toxicol 2002; 21:7781.

56 Preston TJ, Muller WJ, Singh G. Scavenging of extracellular $\mathrm{H} 2 \mathrm{O} 2$ by catalase inhibits the proliferation of HER-2/Neutransformed rat-1 fibroblasts through the induction of a stress response. J Biol Chem 2001; 276:9558-9564.

57 Zhao ZQ. Oxidative stress-elicited myocardial apoptosis during reperfusion. Curr Opin Pharmacol 2004; 4:159-165.

58 Kamata H, Hirata H. Redox regulation of cellular signalling. Cell Signal 1999; 11:1-14.

59 Sundaresan M, Yu ZX, Ferrans VJ, Irani K, Finkel T. Requirement for generation of $\mathrm{H} 2 \mathrm{O} 2$ for platelet-derived growth factor signal transduction. Science 1995; 270:296-299.

60 Guyton KZ, Liu Y, Gorospe M, Xu Q, Holbrook NJ. Activation of mitogen-activated protein kinase by $\mathrm{H} 2 \mathrm{O} 2$. Role in cell survival following oxidant injury. J Biol Chem 1996; 271:4138-4142.

61 Rao GN. Hydrogen peroxide induces complex formation of SHC-Grb2-SOS with receptor tyrosine kinase and activates Ras and extracellular signal-regulated protein kinases group of mitogen-activated protein kinases. Oncogene 1996; 13:713719.

62 Mercurio F, Manning AM. NF-kappaB as a primary regulator of the stress response. Oncogene 1999; 18:6163-6171.

63 Adler V, Yin Z, Fuchs SY, et al. Regulation of JNK signaling by GSTp. EMBO J 1999; 18:1321-1334.

64 Preston TJ, Abadi A, Wilson L, Singh G. Mitochondrial contributions to cancer cell physiology: potential for drug development. Adv Drug Deliv Rev 2001; 49:45-61.

65 Hampton MB, Kettle AJ, Winterbourn CC. Inside the neutrophil phagosome: oxidants, myeloperoxidase, and bacterial killing. Blood 1998; 92:3007-3017.

66 Amstad PA, Krupitza G, Cerutti PA. Mechanism of c-fos induction by active oxygen. Cancer Res 1992; 52:3952-3960.

67 Nose K, Ohba M. Functional activation of the Egr-1 (early growth response-1) gene by hydrogen peroxide. Biochem $J$ 1996; 316 (Pt 2):381-383.

68 Nose K, Shibanuma M, Kikuchi K, et al. Transcriptional activation of early-response genes by hydrogen peroxide in a mouse osteoblastic cell line. Eur J Biochem 1991; 201:99106.

69 Ha HC, Thiagalingam A, Nelkin BD, Casero RA Jr. Reactive oxygen species are critical for the growth and differentiation of medullary thyroid carcinoma cells. Clin Cancer Res 2000; 6:3783-3787.

70 Sundaresan M, Yu ZX, Ferrans VJ, et al. Regulation of reactive-oxygen-species generation in fibroblasts by Rac1. Biochem J 1996; 318 (Pt 2):379-382.

71 Semenza GL. O2-regulated gene expression: transcriptional control of cardiorespiratory physiology by HIF-1. J Appl Physiol 2004; 96:1173-1177; discussion 1170-1172.

72 Semenza GL. HIF-1, O(2), and the 3 PHDs: how animal cells signal hypoxia to the nucleus. Cell 2001; 107:1-3.

73 Zhang H, Gao P, Fukuda R, et al. HIF-1 inhibits mitochondrial biogenesis and cellular respiration in VHL-deficient renal cell carcinoma by repression of C-MYC activity. Cancer Cell 2007; 11:407-420.

74 Lin JD. Minireview: the PGC-1 coactivator networks: chromatin-remodeling and mitochondrial energy metabolism. $\mathrm{Mol}$ Endocrinol 2009; 23:2-10.

75 Kim JW, Tchernyshyov I, Semenza GL, Dang CV. HIF-1mediated expression of pyruvate dehydrogenase kinase: a metabolic switch required for cellular adaptation to hypoxia. Cell Metab 2006; 3:177-185.

76 Papandreou I, Cairns RA, Fontana L, Lim AL, Denko NC. HIF-1 mediates adaptation to hypoxia by actively downregulating mitochondrial oxygen consumption. Cell Metab 2006; 3:187-197.

77 Fukuda R, Zhang H, Kim JW, et al. HIF-1 regulates cytochrome oxidase subunits to optimize efficiency of respiration in hypoxic cells. Cell 2007; 129:111-122.

78 Klimova T, Chandel NS. Mitochondrial complex III regulates hypoxic activation of HIF. Cell Death Differ 2008; 15:660666.

79 Zhou S, Kachhap S, Sun W, et al. Frequency and phenotypic implications of mitochondrial DNA mutations in human squamous cell cancers of the head and neck. Proc Natl Acad Sci USA 2007; 104:7540-7545.

80 Kroemer G. Mitochondrial control of apoptosis: an overview. Biochem Soc Symp 1999; 66:1-15.

81 Johnstone RW, Ruefli AA, Lowe SW. Apoptosis: a link between cancer genetics and chemotherapy. Cell 2002; 108:153164.

82 Liu X, Kim CN, Yang J, Jemmerson R, Wang X. Induction of apoptotic program in cell-free extracts: requirement for dATP and cytochrome $c$. Cell 1996; 86:147-157.

83 Kwong JQ, Henning MS, Starkov AA, Manfredi G. The mitochondrial respiratory chain is a modulator of apoptosis. $J$ Cell Biol 2007; 179:1163-1177.

84 Raha S, Robinson BH. Mitochondria, oxygen free radicals, and apoptosis. Am J Med Genet 2001; 106:62-70.

85 Shen YH, Wang XL, Wilcken DE. Nitric oxide induces and inhibits apoptosis through different pathways. FEBS Lett 1998; 433:125-131.

86 Ghosh JC, Dohi T, Kang BH, Altieri DC. Hsp60 regulation of tumor cell apoptosis. J Biol Chem 2008; 283:5188-5194.

87 Kang BH, Plescia J, Dohi T, et al. Regulation of tumor cell mitochondrial homeostasis by an organelle-specific Hsp90 chaperone network. Cell 2007; 131:257-270.

88 Butow RA, Avadhani NG. Mitochondrial signaling: the retrograde response. Mol Cell 2004; 14:1-15. 
89 Wang H, Morais R. Up-regulation of nuclear genes in response to inhibition of mitochondrial DNA expression in chicken cells. Biochim Biophys Acta 1997; 1352:325-334.

90 Marusich MF, Robinson BH, Taanman JW, et al. Expression of mtDNA and nDNA encoded respiratory chain proteins in chemically and genetically-derived Rho0 human fibroblasts: a comparison of subunit proteins in normal fibroblasts treated with ethidium bromide and fibroblasts from a patient with mtDNA depletion syndrome. Biochim Biophys Acta 1997; 1362:145-159.

91 Freyssenet D, Irrcher I, Connor MK, Di Carlo M, Hood DA. Calcium-regulated changes in mitochondrial phenotype in skeletal muscle cells. Am J Physiol Cell Physiol 2004; 286:C1053-1061.

92 Woo DK, Phang TL, Trawick JD, Poyton RO. Multiple pathways of mitochondrial-nuclear communication in yeast: Intergenomic signaling involves $\mathrm{ABF} 1$ and affects a different set of genes than retrograde regulation. Biochim Biophys Acta 2009; 1789:135-145.

93 Owusu-Ansah E, Yavari A, Mandal S, Banerjee U. Distinct mitochondrial retrograde signals control the G1-S cell cycle checkpoint. Nat Genet 2008; 40:356-361.

94 Selak MA, Armour SM, MacKenzie ED, et al. Succinate links TCA cycle dysfunction to oncogenesis by inhibiting HIFalpha prolyl hydroxylase. Cancer Cell 2005; 7:77-85.

95 Howell AN, Sager R. Tumorigenicity and its suppression in cybrids of mouse and Chinese hamster cell lines. Proc Natl Acad Sci USA 1978; 75:2358-2362.

96 Biswas G, Adebanjo OA, Freedman BD, et al. Retrograde $\mathrm{Ca} 2+$ signaling in $\mathrm{C} 2 \mathrm{C} 12$ skeletal myocytes in response to mitochondrial genetic and metabolic stress: a novel mode of inter-organelle crosstalk. EMBO J 1999; 18:522-533.

97 Amuthan G, Biswas G, Ananadatheerthavarada HK, et al. Mitochondrial stress-induced calcium signaling, phenotypic changes and invasive behavior in human lung carcinoma A549 cells. Oncogene 2002; 21:7839-7849.

98 Amuthan G, Biswas G, Zhang SY, et al. Mitochondria-tonucleus stress signaling induces phenotypic changes, tumor progression and cell invasion. EMBO J 2001; 20:1910-1920.

99 Biswas G, Guha M, Avadhani NG. Mitochondria-to-nucleus stress signaling in mammalian cells: nature of nuclear gene targets, transcription regulation, and induced resistance to apoptosis. Gene 2005; 354:132-139.

100 Guha M, Srinivasan S, Biswas G, Avadhani NG. Activation of a novel calcineurin-mediated insulin-like growth factor-1 receptor pathway, altered metabolism, and tumor cell invasion in cells subjected to mitochondrial respiratory stress. $J$ Biol Chem 2007; 282:14536-14546.

101 Biswas G, Srinivasan S, Anandatheerthavarada HK, Avadhani NG. Dioxin-mediated tumor progression through activation of mitochondria-to-nucleus stress signaling. Proc Natl Acad Sci USA 2008; 105:186-191.

102 Kulawiec M, Arnouk H, Desouki MM, et al. Proteomic analysis of mitochondria-to-nucleus retrograde response in human cancer. Cancer Biol Ther 2006; 5:967-975.

103 Park SY, Lee S, Park KS, Lee HK, Lee W. Proteomic analysis of cellular change involved in mitochondria-to-nucleus communication in L6 GLUT4myc myocytes. Proteomics 2006; 6:1210-1222.
104 Loffler M, Jockel J, Schuster G, Becker C. Dihydroorotatubiquinone oxidoreductase links mitochondria in the biosynthesis of pyrimidine nucleotides. Mol Cell Biochem 1997; 174:125-129.

105 Traut TW. Physiological concentrations of purines and pyrimidines. Mol Cell Biochem 1994; 140:1-22.

106 Rasmussen AK, Chatterjee A, Rasmussen LJ, Singh KK. Mitochondria-mediated nuclear mutator phenotype in Saccharomyces cerevisiae. Nucleic Acids Res 2003; 31:3909-3917.

107 Desler C, Munch-Petersen B, Stevnsner T, et al. Mitochondria as determinant of nucleotide pools and chromosomal stability. Mutat Res 2007; 625:112-124.

108 Meuth M. The molecular basis of mutations induced by deoxyribonucleoside triphosphate pool imbalances in mammalian cells. Exp Cell Res 1989; 181:305-316.

109 Liu L, Trimarchi JR, Smith PJ, Keefe DL. Mitochondrial dysfunction leads to telomere attrition and genomic instability. Aging Cell 2002; 1:40-46.

110 Salas A, Yao YG, Macaulay V, et al. A critical reassessment of the role of mitochondria in tumorigenesis. PLoS Med 2005; 2:e296.

111 Fang H, Lu J, Wei J, et al. Mitochondrial DNA mutations in the D-loop region may not be frequent in cervical cancer: a discussion on pitfalls in mitochondrial DNA studies. $J$ Cancer Res Clin Oncol 2009.

112 He L, Luo L, Proctor SJ, et al. Somatic mitochondrial DNA mutations in adult-onset leukaemia. Leukemia 2003; 17:24872491.

113 Carew JS, Zhou Y, Albitar M, et al. Mitochondrial DNA mutations in primary leukemia cells after chemotherapy: clinical significance and therapeutic implications. Leukemia 2003; 17:1437-1447.

114 Linnartz B, Anglmayer R, Zanssen S. Comprehensive scanning of somatic mitochondrial DNA alterations in acute leukemia developing from myelodysplastic syndromes. Cancer Res 2004; 64:1966-1971.

115 Habano W, Sugai T, Yoshida T, Nakamura S. Mitochondrial gene mutation, but not large-scale deletion, is a feature of colorectal carcinomas with mitochondrial microsatellite instability. Int J Cancer 1999; 83:625-629.

116 Nishikawa M, Oshitani N, Matsumoto T, et al. Accumulation of mitochondrial DNA mutation with colorectal carcinogenesis in ulcerative colitis. Br J Cancer 2005; 93:331-337.

117 Allalunis-Turner J, Ma I, Hanson J, Pearcey RG. mtDNA mutations in invasive cervix tumors: a retrospective analysis. Cancer Lett 2006; 243:193-201.

118 Jin X, Zhang J, Gao Y, et al. Relationship between mitochondrial DNA mutations and clinical characteristics in human lung cancer. Mitochondrion 2007; 7:347-353.

119 Durham SE, Krishnan KJ, Betts J, Birch-Machin MA. Mitochondrial DNA damage in non-melanoma skin cancer. $\mathrm{Br} J$ Cancer 2003; 88:90-95.

120 Girald-Rosa W, Vleugels RA, Musiek AC, Sligh JE. Highthroughput mitochondrial genome screening method for nonmelanoma skin cancer using multiplexed temperature gradient capillary electrophoresis. Clin Chem 2005; 51:305-311.

121 Costa-Guda J, Tokura T, Roth SI, Arnold A. Mitochondrial DNA mutations in oxyphilic and chief cell parathyroid adenomas. BMC Endocr Disord 2007; 7:8. 
122 Yeh JJ, Lunetta KL, van Orsouw NJ, et al. Somatic mitochondrial DNA (mtDNA) mutations in papillary thyroid carcinomas and differential mtDNA sequence variants in cases with thyroid tumours. Oncogene 2000; 19:2060-2066.

123 Gasparre G, Porcelli AM, Bonora E, et al. Disruptive mitochondrial DNA mutations in complex I subunits are markers of oncocytic phenotype in thyroid tumors. Proc Natl Acad Sci USA 2007; 104:9001-9006.

124 Abu-Amero KK, Alzahrani AS, Zou M, Shi Y. Association of mitochondrial DNA transversion mutations with familial medullary thyroid carcinoma/multiple endocrine neoplasia type 2 syndrome. Oncogene 2006; 25:677-684.

125 Bonora E, Porcelli AM, Gasparre G, et al. Defective oxidative phosphorylation in thyroid oncocytic carcinoma is associated with pathogenic mitochondrial DNA mutations affecting complexes I and III. Cancer Res 2006; 66:6087-6096.

126 Maximo V, Soares P, Lima J, Cameselle-Teijeiro J, SobrinhoSimoes M. Mitochondrial DNA somatic mutations (point mutations and large deletions) and mitochondrial DNA variants in human thyroid pathology: a study with emphasis on Hurthle cell tumors. Am J Pathol 2002; 160:1857-1865.

127 Rogounovitch T, Saenko V, Yamashita S. Mitochondrial DNA and human thyroid diseases. Endocr J 2004; 51:265-277.

128 Mayr JA, Meierhofer D, Zimmermann F, et al. Loss of complex I due to mitochondrial DNA mutations in renal oncocytoma. Clin Cancer Res 2008; 14:2270-2275.

129 Mithani SK, Taube JM, Zhou S, et al. Mitochondrial mutations are a late event in the progression of head and neck squamous cell cancer. Clin Cancer Res 2007; 13:4331-4335.

130 Sui G, Zhou S, Wang J, et al. Mitochondrial DNA mutations in preneoplastic lesions of the gastrointestinal tract: a biomarker for the early detection of cancer. Mol Cancer 2006; 5:73.

131 Jeronimo C, Nomoto S, Caballero OL, et al. Mitochondrial mutations in early stage prostate cancer and bodily fluids. Oncogene 2001; 20:5195-5198.

132 Parrella P, Xiao Y, Fliss M, et al. Detection of mitochondrial DNA mutations in primary breast cancer and fine-needle aspirates. Cancer Res 2001; 61:7623-7626.

133 Maximo V, Soares P, Seruca R, et al. Microsatellite instability, mitochondrial DNA large deletions, and mitochondrial DNA mutations in gastric carcinoma. Genes Chromosomes Cancer 2001; 32:136-143.

134 Gallardo ME, Moreno-Loshuertos R, Lopez C, et al. m. $6267 \mathrm{G}>\mathrm{A}$ : a recurrent mutation in the human mitochondrial DNA that reduces cytochrome $c$ oxidase activity and is associated with tumors. Hum Mutat 2006; 27:575-582.

135 Tan DJ, Bai RK, Wong LJ. Comprehensive scanning of somatic mitochondrial DNA mutations in breast cancer. Cancer Res 2002; 62:972-976.

136 Wong LJ, Lueth M, Li XN, Lau CC, Vogel H. Detection of mitochondrial DNA mutations in the tumor and cerebrospinal fluid of medulloblastoma patients. Cancer Res 2003; 63:38663871.

137 Prior SL, Griffiths AP, Baxter JM, et al. Mitochondrial DNA mutations in oral squamous cell carcinoma. Carcinogenesis 2006; 27:945-950.

138 Tan DJ, Chang J, Chen WL, et al. Somatic mitochondrial DNA mutations in oral cancer of betel quid chewers. Ann NY
Acad Sci 2004; 1011:310-316.

139 Tan DJ, Chang J, Chen WL, et al. Novel heteroplasmic frameshift and missense somatic mitochondrial DNA mutations in oral cancer of betel quid chewers. Genes Chromosomes Cancer 2003; 37:186-194.

140 Nagy A, Wilhelm M, Kovacs G. Mutations of mtDNA in renal cell tumours arising in end-stage renal disease. J Pathol 2003; 199:237-242.

141 Abu-Amero KK, Alzahrani AS, Zou M, Shi Y. High frequency of somatic mitochondrial DNA mutations in human thyroid carcinomas and complex I respiratory defect in thyroid cancer cell lines. Oncogene 2005; 24:1455-1460.

142 Hibi K, Nakayama H, Yamazaki T, et al. Mitochondrial DNA alteration in esophageal cancer. Int $J$ Cancer 2001; 92:319321.

143 Fliss MS, Usadel H, Caballero OL, et al. Facile detection of mitochondrial DNA mutations in tumors and bodily fluids. Science 2000; 287:2017-2019.

144 Nagy A, Wilhelm M, Sukosd F, Ljungberg B, Kovacs G. Somatic mitochondrial DNA mutations in human chromophobe renal cell carcinomas. Genes Chromosomes Cancer 2002; 35:256-260.

145 Tzen CY, Mau BL, Wu TY. ND4 mutation in transitional cell carcinoma: does mitochondrial mutation occur before tumorigenesis? Mitochondrion 2007; 7:273-278.

146 Kiebish MA, Seyfried TN. Absence of pathogenic mitochondrial DNA mutations in mouse brain tumors. BMC Cancer 2005; 5:102.

147 Gomez-Zaera M, Abril J, Gonzalez L, et al. Identification of somatic and germline mitochondrial DNA sequence variants in prostate cancer patients. Mutat Res 2006; 595:42-51.

148 Habano W, Nakamura S, Sugai T. Microsatellite instability in the mitochondrial DNA of colorectal carcinomas: evidence for mismatch repair systems in mitochondrial genome. Oncogene 1998; 17:1931-1937.

149 Khrapko K, Nekhaeva E, Kraytsberg Y, Kunz W. Clonal expansions of mitochondrial genomes: implications for in vivo mutational spectra. Mutat Res 2003; 522:13-19.

150 Witte J, Lehmann S, Wulfert M, Yang Q, Roher HD. Mitochondrial DNA mutations in differentiated thyroid cancer with respect to the age factor. World J Surg 2007; 31:51-59.

151 Tan DJ, Chang J, Liu LL, et al. Significance of somatic mutations and content alteration of mitochondrial DNA in esophageal cancer. BMC Cancer 2006; 6:93.

152 Habano W, Sugai T, Nakamura SI, et al. Microsatellite instability and mutation of mitochondrial and nuclear DNA in gastric carcinoma. Gastroenterology 2000; 118:835-841.

153 Chen JZ, Gokden N, Greene GF, Green B, Kadlubar FF. Simultaneous generation of multiple mitochondrial DNA mutations in human prostate tumors suggests mitochondrial hypermutagenesis. Carcinogenesis 2003; 24:1481-1487.

154 Pang LJ, Shao JY, Liang XM, Xia YF, Zeng YX. Mitochondrial DNA somatic mutations are frequent in nasopharyngeal carcinoma. Cancer Biol Ther 2008; 7:198-207.

155 Kirches E, Krause G, Warich-Kirches M, et al. High frequency of mitochondrial DNA mutations in glioblastoma multiforme identified by direct sequence comparison to blood samples. Int J Cancer 2001; 93:534-538.

156 Lievre A, Chapusot C, Bouvier AM, et al. Clinical value of 
mitochondrial mutations in colorectal cancer. $J$ Clin Oncol 2005; 23:3517-3525.

157 Wong LJ, Tan DJ, Bai RK, Yeh KT, Chang J. Molecular alterations in mitochondrial DNA of hepatocellular carcinomas: is there a correlation with clinicopathological profile? $\mathrm{J} \mathrm{Med}$ Genet 2004; 41:e65.

$158 \mathrm{Kim}$ HS, Lim HS, Lee SH, et al. Mitochondrial microsatellite instability of colorectal cancer stroma. Int J Cancer 2006; 119:2607-2611.

159 Wang CY, Wang HW, Yao YG, Kong QP, Zhang YP. Somatic mutations of mitochondrial genome in early stage breast cancer. Int J Cancer 2007; 121:1253-1256.

160 Parrella P, Seripa D, Matera MG, et al. Mutations of the D310 mitochondrial mononucleotide repeat in primary tumors and cytological specimens. Cancer Lett 2003; 190:73-77.

161 Zhu W, Qin W, Bradley P, et al. Mitochondrial DNA mutations in breast cancer tissue and in matched nipple aspirate fluid. Carcinogenesis 2005; 26:145-152.

162 Tseng LM, Yin PH, Chi CW, et al. Mitochondrial DNA mutations and mitochondrial DNA depletion in breast cancer. Genes Chromosomes Cancer 2006; 45:629-638.

$163 \mathrm{Yu}$ M, Shi Y, Zhang F, et al. Sequence variations of mitochondrial DNA D-loop region are highly frequent events in familial breast cancer. J Biomed Sci 2008; 15:535-543.

164 Bertagnolli AC, Soares P, van Asch B, et al. An assessment of the clonality of the components of canine mixed mammary tumours by mitochondrial DNA analysis. Vet $J 2008$ Aug 25. doi:10.1016/j.tvj1.2008.07.005

165 Rosson D, Keshgegian AA. Frequent mutations in the mitochondrial control region DNA in breast tissue. Cancer Lett 2004; 215:89-94.

166 Chen D, Zhan H. Study on the mutations in the D-loop region of mitochondrial DNA in cervical carcinoma. $J$ Cancer Res Clin Oncol 2008; 135:291-295.

167 Sharma H, Singh A, Sharma C, Jain SK, Singh N. Mutations in the mitochondrial DNA D-loop region are frequent in cervical cancer. Cancer Cell Int 2005; 5:34.

168 Legras A, Lievre A, Bonaiti-Pellie C, et al. Mitochondrial D310 mutations in colorectal adenomas: an early but not causative genetic event during colorectal carcinogenesis. Int $J$ Cancer 2008; 122:2242-2248.

169 Hibi K, Nakayama H, Yamazaki T, et al. Detection of mitochondrial DNA alterations in primary tumors and corresponding serum of colorectal cancer patients. Int J Cancer 2001; 94:429-431.

170 Guleng G, Lovig T, Meling GI, Andersen SN, Rognum TO. Mitochondrial microsatellite instability in colorectal carcinomas--frequency and association with nuclear microsatellite instability. Cancer Lett 2005; 219:97-103.

$171 \mathrm{Xu} \mathrm{L}, \mathrm{Hu} \mathrm{Y}$, Chen $\mathrm{B}$, et al. Mitochondrial polymorphisms as risk factors for endometrial cancer in southwest China. Int $J$ Gynecol Cancer 2006; 16:1661-1667.

172 Liu VW, Yang HJ, Wang Y, et al. High frequency of mitochondrial genome instability in human endometrial carcinomas. Br J Cancer 2003; 89:697-701.

173 Wang Y, Xue WC, Liu VW, Ngan HY. Detection of mosaic pattern of mitochondrial DNA alterations in different populations of cells from the same endometrial tumor. Mitochondrion 2007; 7:171-175.
174 Kumimoto H, Yamane Y, Nishimoto Y, et al. Frequent somatic mutations of mitochondrial DNA in esophageal squamous cell carcinoma. Int J Cancer 2004; 108:228-231.

175 Abnet CC, Huppi K, Carrera A, et al. Control region mutations and the 'common deletion' are frequent in the mitochondrial DNA of patients with esophageal squamous cell carcinoma. BMC Cancer 2004; 4:30.

176 Lievre A, Blons H, Houllier AM, et al. Clinicopathological significance of mitochondrial D-Loop mutations in head and neck carcinoma. Br J Cancer 2006; 94:692-697.

177 Lee HC, Yin PH, Lin JC, et al. Mitochondrial genome instability and mtDNA depletion in human cancers. Ann N Y Acad Sci 2005; 1042:109-122.

$178 \mathrm{Wu} \mathrm{CW}$, Yin PH, Hung WY, et al. Mitochondrial DNA mutations and mitochondrial DNA depletion in gastric cancer. Genes Chromosomes Cancer 2005; 44:19-28.

179 Lee HC, Hsu LS, Yin PH, Lee LM, Chi CW. Heteroplasmic mutation of mitochondrial DNA D-loop and 4977-bp deletion in human cancer cells during mitochondrial DNA depletion. Mitochondrion 2007; 7:157-163.

180 Tamori A, Nishiguchi S, Nishikawa M, et al. Correlation between clinical characteristics and mitochondrial D-loop DNA mutations in hepatocellular carcinoma. J Gastroenterol 2004; 39:1063-1068.

181 Yoneyama H, Hara T, Kato Y, et al. Nucleotide sequence variation is frequent in the mitochondrial DNA displacement loop region of individual human tumor cells. Mol Cancer Res 2005; 3:14-20.

182 Kurtz A, Lueth M, Kluwe L, et al. Somatic mitochondrial DNA mutations in neurofibromatosis type 1-associated tumors. Mol Cancer Res 2004; 2:433-441.

183 Suzuki M, Toyooka S, Miyajima K, et al. Alterations in the mitochondrial displacement loop in lung cancers. Clin Cancer Res 2003; 9:5636-5641.

184 Pai CY, Hsieh LL, Lee TC, et al. Mitochondrial DNA sequence alterations observed between blood and buccal cells within the same individuals having betel quid (BQ)-chewing habit. Forensic Sci Int 2006; 156:124-130.

185 Maki J, Robinson K, Reguly B, et al. Mitochondrial genome deletion aids in the identification of false- and true-negative prostate needle core biopsy specimens. Am J Clin Pathol 2008; 129:57-66.

186 Chen JZ, Gokden N, Greene GF, Mukunyadzi P, Kadlubar FF. Extensive somatic mitochondrial mutations in primary prostate cancer using laser capture microdissection. Cancer Res 2002; 62:6470-6474.

187 Chen JZ, Kadlubar FF. Mitochondrial mutagenesis and oxidative stress in human prostate cancer. J Environ Sci Health $C$ Environ Carcinog Ecotoxicol Rev 2004; 22:1-12.

188 Lohrer HD, Hieber L, Zitzelsberger H. Differential mutation frequency in mitochondrial DNA from thyroid tumours. Carcinogenesis 2002; 23:1577-1582.

189 Van Trappen PO, Cullup T, Troke R, et al. Somatic mitochondrial DNA mutations in primary and metastatic ovarian cancer. Gynecol Oncol 2007; 104:129-133.

190 Kose K, Hiyama T, Tanaka S, et al. Nuclear and mitochondrial DNA microsatellite instability in gastrointestinal stromal tumors. Pathobiology 2006; 73:93-97.

191 Nishikawa M, Nishiguchi S, Shiomi S, et al. Somatic muta- 
tion of mitochondrial DNA in cancerous and noncancerous liver tissue in individuals with hepatocellular carcinoma. Cancer Res 2001; 61:1843-1845.

192 Lee HC, Li SH, Lin JC, et al. Somatic mutations in the Dloop and decrease in the copy number of mitochondrial DNA in human hepatocellular carcinoma. Mutat Res 2004; 547:7178.

193 Tamura G, Nishizuka S, Maesawa C, et al. Mutations in mitochondrial control region DNA in gastric tumours of Japanese patients. Eur J Cancer 1999; 35:316-319.

194 Montanini L, Regna-Gladin C, Eoli M, et al. Instability of mitochondrial DNA and MRI and clinical correlations in malignant gliomas. J Neurooncol 2005; 74:87-89.

195 Kirches E, Krause G, Weis S, Mawrin C, Dietzmann K. Comparison between mitochondrial DNA sequences in low grade astrocytomas and corresponding blood samples. Mol Pathol 2002; 55:204-206.

196 Miyazono F, Schneider PM, Metzger R, et al. Mutations in the mitochondrial DNA D-Loop region occur frequently in adenocarcinoma in Barrett's esophagus. Oncogene 2002; 21:3780-3783.

197 Guo XG, Guo QN. Mutations in the mitochondrial DNA D-
Loop region occur frequently in human osteosarcoma. Cancer Lett 2006; 239:151-155.

198 Wardell TM, Ferguson E, Chinnery PF, et al. Changes in the human mitochondrial genome after treatment of malignant disease. Mutat Res 2003; 525:19-27.

199 Tang M, Baez S, Pruyas M, et al. Mitochondrial DNA mutation at the D310 (displacement loop) mononucleotide sequence in the pathogenesis of gallbladder carcinoma. Clin Cancer Res 2004; 10:1041-1046.

200 El Meziane A, Lehtinen SK, Holt IJ, Jacobs HT. Mitochondrial tRNALeu isoforms in lung carcinoma cybrid cells containing the np 3243 mtDNA mutation. Hum Mol Genet 1998; 7:2141-2147.

201 Sangkhathat S, Kusafuka T, Yoneda A, et al. Renal cell carcinoma in a pediatric patient with an inherited mitochondrial mutation. Pediatr Surg Int 2005; 21:745-748.

202 Lombes A, Bories D, Girodon E, et al. The first pathogenic mitochondrial methionine tRNA point mutation is discovered in splenic lymphoma. Hum Mutat 1998; Suppl 1:S175-S183.

203 Han CB, Xin Y, Yang XF, et al. [Mutation of mitochondrial $12 \mathrm{~S}$ rRNA in gastric carcinomas and its significance]. Zhonghua Zhong Liu Za Zhi 2005; 27:260-264. 